\title{
As políticas públicas de livro didático no Brasil: editais do PNLD de Biologia em questão
}

\section{The public policies of textbook in Brazil: publications of the PNLD of Biology in question}

\author{
Regiane Machado de Sousa Pinheiro* \\ Adda Daniela Lima Figueiredo Echalar* \\ José Rildo de Oliveira Queiroz*
}

\begin{abstract}
RESUMO
O livro didático é um recurso decorrente de um processo de múltiplas determinações e faz parte da história da Educação Brasileira. Este artigo caracteriza as políticas públicas brasileiras voltadas para o livro didático, estabelecendo relações entre os acontecimentos extraescolares ligados à política e ao mercado do livro didático e suas implicações no contexto da Biologia, enquanto disciplina escolar. Nesse contexto, buscamos compreender a lógica dos editais do Programa Nacional do Livro Didático (PNLD), em especial, de Biologia, de modo a explicar as conjunturas que demarcam o Programa. Tendo como base teórico-metodológica a lógica dialética, analisamos os PNLD de Biologia em suas relações de totalidadeparticularidade com os contextos sócio-históricos da educação, por meio de análise documental e exploratória. Concluímos que o modo como é conduzida essa política pública tem favorecido a formação de oligopólios para o ensino que amplia a obtenção do lucro de grandes grupos empresariais, o que estigmatiza o livro didático como mercadoria.

Palavras-chave: Educação Básica. Historicidade. PNLD. Recurso didático.
\end{abstract}

*Universidade Federal de Goiás. Programa de Pós-Graduação em Educação em Ciências e Matemática. Goiânia, Góias, Brasil. E-mail: regianemachado0311@gmail.com - http://orcid. org/0000-0001-7960-6539 E-mail: adda.daniela@ufg.br - http://orcid.org/0000-0003-3026-8860 E-mail: rildo@ufg.br - http://orcid.org/0000-0002-3789-7339 


\begin{abstract}
The textbook is a resource resulting from a multiple determinations process and is part of the history of Brazilian education. In this sense, this article characterizes the Brazilian public policies towards textbooks, establishing relations between the extra-scholastic events linked to politics and the textbook market and their implications in the context of Biology as a school subject. In this context, we seek to understand the details of the Programa Nacional do Livro Didático (PNLD) [National Program of the Textbook], especially for Biology, to explain the conjunctures that demarcate the Program. Having as the theoretical and methodological basis the dialectic logic, we analyzed the Biology PNLD in its totality-particularity relations, with the social-historical contexts of education, through documentary and exploratory analysis. We conclude that the way this public policy is conducted has favored the formation of oligopolies for teaching that expands the profitability of large business groups, which stigmatizes the textbook as a commodity.
\end{abstract}

Keywords: Basic Education. Historicity. PNLD. Didactic resource.

\title{
Introdução
}

O livro didático (LD) faz parte da história da Educação Brasileira, seja na compreensão das práticas escolares, nas concepções de ensino e aprendizagem e/ou pela discussão em torno de sua função na democratização de saberes socialmente legitimados (ALBUQUERQUE; FERREIRA, 2019). Esses, por sua vez, se relacionam com os diferentes campos de conhecimento e modos de compreender a natureza de cada Ciência. Além disso, o LD pode ser compreendido pelo viés dos interesses econômicos em volta de sua produção e comercialização, mediante os investimentos de governo nos programas de avaliação (CASTRO; LOPES, 2019; DI GIORGI et al., 2014), pelo debate dos que possuem acesso ou não a ele e sobre seu papel como possível estruturador da atividade docente (MARTINS, 2012).

Selles e Ferreira (2004) situam o uso do LD sob uma tripla dimensão pedagógica, a saber: a dimensão do currículo, da ação didática e de formação de professores. No âmbito da dimensão curricular, o LD fundamenta suas intenções tanto nas comunidades disciplinares quanto nas autoridades educacionais, devido ao PNLD, que formaliza as intencionalidades educativas do discurso do Ministério da Educação (MEC) nos materiais didáticos por ele organizados. Quanto à ação didática, observa-se que o LD traz, além dos conteúdos a serem 
ensinados, uma proposta pedagógica que pode influenciar, de modo decisivo, a atuação do professor, bem como direcionar currículos e processos de formação continuada. E, por fim, sobre a formação de professores o LD se intercala num caminho que vai da universidade à escola, no qual é aceito como possível produto que contém os conteúdos científicos para uma formação mais sólida. Sendo assim, o LD é um recurso didático que pode determinar decisivamente e, talvez de forma excessiva, os conteúdos e estratégias de ensino (LAJOLO, 1996).

O LD representa um objeto de estudo complexo e que merece discussões permanentes e atuais, visto que é necessário observar todos os contextos envolvidos no processo de avaliação, escolha e utilização na sala de aula (MARTINS; EICHELER, 2020). Entendemos que a realidade não se apresenta de forma explícita e imediata, ao contrário, são necessárias análises com enriquecimento teórico para indicar os elementos que fundamentam a essência do fenômeno em estudo, se constituindo a síntese do problema investigado (LEFEBVRE, 1991). Nele nem sempre está explícito a intencionalidade epistemológica e pedagógica do autor, dificultando os caminhos intencionais para a atuação docente, bem como a participação dos professores na análise e crítica da realidade concreta.

Nosso interesse se pauta no reconhecimento do LD como um recurso didático decorrente de um processo com múltiplas determinações, dentre elas a historicidade do PNLD no Brasil na relação com a área a ser ensinada - a Biologia. Assim, por meio das relações "parte-todo", analisamos o processo de aprovação desses livros por parte do PNLD de Biologia.

Apesar da historicidade do LD ser relativamente conhecida pela academia, ela não é única a todas as áreas do conhecimento. Sua historicidade está vinculada não somente aos direcionamentos das políticas nacionais, mas também à lógica dos contextos históricos de cada Ciência que se leciona e de constituição de cada disciplina escolar na Educação Básica. Portanto, neste trabalho, explicitamos o processo de construção histórica do PNLD, na relação entre os acontecimentos ligados à política, ao mercado do $\mathrm{LD}$ e na relação singular ao contexto da Biologia, enquanto disciplina escolar. Para tanto, objetivamos responder ao seguinte questionamento: quais contextos constituíram à política nacional do $\mathrm{LD}$ no Brasil, em especial, os editais e coleções aprovadas no PNLD de Biologia? Buscamos compreender a lógica dos editais do PNLD de Biologia, de modo a explicar conjunturas que demarcam o Programa.

O artigo, então, está organizado em quatro seções: 1. Percursos da pesquisa; 2. Historicidade do livro didático e do PNLD no Brasil: uma análise com foco na Biologia; 3. PNLD de Biologia: suas relações e intencionalidades; e 4. Considerações finais. 


\section{Percursos da pesquisa}

Ao adotar a lógica dialética como base teórico-metodológica para essa investigação, buscamos ir para além do aparente, no desvelar da concretude da produção do LD. Para tanto, consideramos relevante a historicidade desse recurso didático, pois a realidade é historicamente construída por múltiplas determinações e o LD é um dos produtos dessa construção. Nessa perspectiva teórica, a historicidade representa a dinâmica, o movimento de construção e transformação do objeto em investigação (políticas públicas brasileiras voltadas para o LD) e para entender esse processo é fundamental buscar conhecer a totalidade e contradições que a envolvem (KOPNIN, 1978; LEFEBVRE, 1991).

$\mathrm{Na}$ produção do conhecimento teórico apresentado, desenvolvemos a exposição da pesquisa partindo do concreto: as relações históricas que constituíram o LD enquanto políticas públicas brasileiras para a Educação Básica. De tal modo, pautamo-nos, inicialmente, em uma revisão sistemática de literatura sobre as nuances históricas do PNLD no Brasil e suas interfaces para o LD em seus contextos da área do ensino de Biologia. Temos em vista que analisar a história do livro passa por pesquisar sua gênese, sua natureza, seus significados mais profundos com relação ao saber e ao conhecimento, pois o LD "tem um percurso e tempo históricos próprios, no qual sua representação e apropriação se documentam, explicam e narram no quadro da história cultural" (MAGALHÃES, 2006, p. 14).

O nosso corpus de análise foram os editais, guias de livros didáticos e coleções de Biologia aprovadas nos PNLD realizados de 2007 a 2018. Esses documentos foram encontrados no site do Fundo Nacional de Desenvolvimento da Educação (FNDE). Desse modo, realizamos uma análise documental e exploratória desses documentos, pois possibilitou que o investigador buscasse nos documentos diferentes significados para a organização da pesquisa, além de instigar ideias para pesquisas posteriores ao apontar aspectos que podem ser mais discutidos por meio de outros métodos.

Após a constituição dos dados, pautados na lógica dialética, buscamos articular os documentos elencados com referenciais teóricos que discutem sobre o LD e o PNLD. Em seguida, organizamos uma comparação entre os PNLD de Biologia, observando as editoras participantes do processo e os autores de cada uma das coleções aprovadas nos Programas, com a intenção de constatar a possível relação de recorrência nas coleções aprovadas.

Buscamos avançar teoricamente na discussão quanto as políticas públicas voltadas ao LD, por meio de um movimento em constante transformação, partindo da realidade do empírico para alcançar o concreto pensado, tendo 
em vista que não podemos "nos bastar apenas o que é visível aos olhos, pois o conhecimento da realidade, em sua objetividade, requer a visibilidade da máxima inteligência dos homens (MARTINS, 2006, p. 10, grifos da autora). Assim, articulamos a discussão histórica e a coleta empírica dos dados (editais e coleções de biologia aprovadas nos PNLD), agregando os elementos que fundamentam esse recurso didático.

\section{Historicidade do livro didático e do PNLD no Brasil: uma análise com foco na Biologia}

As políticas públicas do LD iniciaram em 1929, com a constituição do Instituto Nacional do Livro (INL), o qual cooperou com o processo e produção do LD. Anos depois, foi assinado o Decreto-Lei $\mathrm{n}^{\circ}$ 1006, de 30 de dezembro de 1938 (BRASIL, 1939), que instituía a Comissão Nacional do Livro Didático (CNLD), anunciando a primeira política de controle, produção e circulação de LD no país.

Ademais, nesse decreto-lei, encontra-se a primeira definição do que deve ser um LD no contexto das políticas públicas. Esse deveria ser organizado na forma de compêndios - livros que exibiam, total ou parcialmente, a matéria das disciplinas presentes nos programas escolares. Há também a definição dos livros de leitura de classe - livros usados para leitura dos alunos em aula (BRASIL, 1939; DI GIORGI et al., 2014).

Com o fim da ditadura do Estado Novo, em 1945, foi promulgado o Decreto-Lei $n^{\circ}$ 8.460, de 26 de dezembro de 1945 (BRASIL, 1945). Esta lei concretiza a legislação sobre as condições de produção, importação e utilização do LD, atribuindo autonomia ao professor para a escolha do livro a ser utilizado em sala de aula. O poder de legislar sobre o LD centralizou-se no nível federal, permitindo aos Estados ter a responsabilidade pelo processo de adoção de livros nos estabelecimentos de ensino brasileiros, mas com a criação de CNLD em alguns Estados essa função foi descentralizada (HÖFLING, 2006).

No contexto das décadas de 1950-60, EUA e Inglaterra propuseram uma reforma educacional na tentativa de diminuir uma educação deficiente em Ciências. Assim, estes países produziram coleções de LD para o Ensino Médio, decorrentes da associação entre cientistas, educadores e professores, provocando a reestruturação curricular em diversos países liderados por essas nações (FERREIRA; SELLES, 2005). No caso do Brasil, houve adaptação dos projetos curriculares, de maneira menos intensiva no contexto escolar, com a criação dos kits escolares e a tradução de coleções dos livros didáticos. 
No contexto da conjuntura militar, na década de 1960, o MEC realizou diversas discussões sobre o papel do LD na Educação. Em parceria com instituições de outros países, recomendou-se a necessidade de regulamentar e controlar a produção dos livros. Assim, em 1966, constituiu-se um acordo entre o MEC e a Agência Norte-Americana para o Desenvolvimento Internacional (USAID) que permitiu a criação da Comissão do Livro Técnico e Livro Didático (COLTED). Porém, essa "ajuda" norte-americana foi interpretada pelos pesquisadores da área da Educação como um mecanismo de controle sobre o processo educacional no Brasil, tanto no âmbito do mercado quanto no da ideologia.

Ainda na década de 60, a USAID custeou a publicação da coleção de LD produzida pela equipe do Biological Sciences Curriculum Study (BSCS), traduzida e adaptada pelo Instituto Brasileiro de Educação, Ciência e Cultura (IBECC). Foram criadas três versões do BSCS para o ensino de Biologia (organizadas em torno de temas centrais: Biologia Molecular, Citologia e Ecologia) (MARANDINO; SELLES; FERREIRA, 2009).

Essa iniciativa contou com apoio governamental para reformar os conteúdos da disciplina escolar Biologia, a fim de tentar abandonar a visão fragmentada dessa ciência, sustentando e disseminando a crença em uma Biologia moderna e unificada. Todavia, ao final dos anos 1970, essas versões perderam espaço devido à redução do apoio financeiro que recebiam.

Com o objetivo de espalhar coleções de LD de caráter empírico para o ensino de Ciências, o IBECC, com o apoio de recursos financeiros estrangeiros e parceria com a Editora Abril, produziu materiais de ensino específicos para laboratório e adaptou à produção do LD. Esses materiais eram kits com informações da área de estudo e experimentos de um cientista, como Newton, Pasteur, Galileu, expondo informações sobre a área de estudo deles, além das orientações para realizar essas experiências. Tal instituto passou a ser referência na produção de livros didáticos na época, tornando-os agentes renovadores do ensino de Ciências (MARANDINO; SELLES; FERREIRA, 2009).

Em consonância a lógica posta pelo material produzido pelo IBECC, nos anos de 1970, os programas curriculares priorizavam o ensino experimental, valorizando o método científico e a instrução programada do ensino. Em virtude disso, a quinta edição do Compêndio de Biologia Geral (LD do Colégio Pedro II) aumentou significativamente as páginas do conteúdo de Citologia, ressaltando as atividades com experimentos, na busca de construir um currículo focado no fazer do estudante em atividades práticas e experimentais (CASSAB et al., 2012).

Em 1976, por meio do Decreto $\mathrm{n}^{\circ} 77.107$ (BRASIL, 1976), o Instituto Nacional do Livro (INL), criado em 1937 e que desenvolvia o Programa do Livro Didático para o Ensino Fundamental (PLIDEF), foi extinto e as atividades 
relacionadas aos livros, bem como os recursos financeiros do programa de edição de livros passaram a ser de competência da Fundação Nacional do Material Escolar - FENAME (ALBUQUERQUE; FERREIRA, 2019; BRASIL, 1976).

Essa mudança proporcionou um aumento na publicação de livros e a criação de um mercado seguro para as editoras. Isto se deu devido ao interesse do governo federal em adquirir boa parte da tiragem de livros para distribuir às escolas (HÖFLING, 2000). Neste momento, o Estado assumiu a função de financiador dos livros, ainda que para fins diversos, permanecendo até os dias atuais.

As políticas educacionais da década de 1980 são marcadas por fatos sociais. Os diversos programas de assistência do governo do ex-presidente José Sarney, como o Programa Nacional de Alimentação Escolar (PNAE), o Programa do Livro Didático (PLID), programas editoriais, de material escolar e de bolsas de estudos, foram vinculados às políticas assistencialistas.

Esse tipo de política foi criticada por pesquisadores do LD no Brasil, os quais apontaram alguns problemas decorrentes dessa ação governamental: "dificuldades de distribuição do livro dentro dos prazos previstos, lobbies das empresas e editoras junto aos órgãos estatais responsáveis, autoritarismo implícito na tomada de decisões na escolha do livro etc." (FREITAG; MOTTA; COSTA, 1987, p. 9).

Em maio de 1985, o Governo Sarney apresentou a proposta "Educação para Todos: caminho para mudança" (BRASIL, 1985a) ${ }^{1}$ com o discurso de obter a universalização do ensino de $1^{\circ}$ grau, com padrões de qualidade satisfatórios. Dentre os principais problemas a serem enfrentados para a melhoria da Educação Brasileira à época estavam: baixa produtividade no ensino e a inexistência de um fluxo adequado de recursos financeiros para a Educação Básica que possibilitassem mudanças na política pública para o LD e buscassem integrar as camadas populares nas escolas (CASSIANO, 2007).

Como reflexo dessas críticas e atendendo as demandas de ampliação da instrução por brasileiros a fim de ampliar nosso crescimento econômico, instituiu-se o PNLD por meio do Decreto $\mathrm{n}^{\circ}$ 91.542, de 19 de agosto de 1985 (BRASIL, 1985b), representando um marco na história do LD no Brasil.

Esse novo programa trouxe várias mudanças significativas que compõem as características atuais do PNLD, como: a indicação de livros pelo professor, a reutilização do livro, a extensão da oferta dos livros e o fim da participação financeira dos estados. Ademais, esse decreto estabeleceu o atendimento de todos os alunos do Ensino Fundamental das escolas públicas federais, estaduais, territoriais, municipais e comunitárias do país, com prioridade para os componentes básicos "Comunicação e Expressão" e "Matemática" (HÖFLING, 2000). 
Como resultado do compromisso internacional assumido em Jomtien, em 1990, foi estabelecido no Brasil o "Plano Decenal de Educação para Todos" - 1993-2003 (BRASIL, 1993). Esse plano criticou o processo de condução do PNLD, ressaltando problemas ligados à aquisição e distribuição dos livros didáticos, visto que não chegavam na escola no início do ano letivo. Além disso, questionou a qualidade dos livros escolhidos e recebidos pelas escolas.

Com o intuito de adequar-se à realidade do capitalismo, o Programa priorizou o LD como recurso pedagógico essencial ao mercado, ao ensino e à aprendizagem e previa políticas públicas que o privilegiassem. Como decorrência desse plano, em 1994, foi publicada a Definição de Critérios para Avaliação dos Livros Didáticos pelo MEC (CASSIANO, 2007).

Esses critérios resultaram do trabalho de uma comissão governamental que analisou a qualidade dos conteúdos programáticos e dos aspectos pedagógicometodológicos dos livros adquiridos pelo MEC para os anos iniciais do ensino fundamental. Essa comissão identificou que existiam livros com elementos preconceituosos, desatualizados e com erros conceituais.

Em seguida, em 1996, implementou-se o processo de avaliação pedagógica dos livros por meio de comissões divididas por áreas de conhecimento. Essas comissões estabeleceram critérios de análise e avaliação dos LD. Como fruto desse processo, produziu-se os Guias de Livros Didáticos para orientar os professores em suas escolhas. Outrossim, adotou-se medidas que asseguraram a ampliação da aquisição do livro para todas as disciplinas do Ensino Fundamental e a distribuição planejada desses materiais didáticos, sendo elas de ordem conceitual (sem erros ou indução a erros) e política (isentos de preconceito, discriminação, posicionamento político e religioso) (CASSIANO, 2007).

A partir de 1997, a responsabilidade pela política de execução do primeiro PNLD passou a ser fomentado pelo Fundo Nacional de Desenvolvimento da Educação (FNDE), autarquia federal vinculada ao MEC, criada em 1968. O programa foi, então, ampliado, passando a atender estudantes do Ensino Fundamental da rede pública ( $1^{\circ}$ ao $8^{\circ}$ ano), com livros de Língua Portuguesa, Matemática, Ciências, Estudos Sociais, História e Geografia. Para haver o recebimento dos livros determinou-se que as escolas fariam o cadastro anual no Censo Escolar, realizado pelo Instituto Nacional de Estudos e Pesquisas Educacionais (INEP). Quanto à distribuição dos livros, a responsabilidade coube à Empresa Brasileira de Correio e Telégrafos (ECT), a qual exigiu dos Correios do Brasil uma logística de grande complexidade e demanda (CASSIANO, 2007). 
A ampliação do PNLD de 1999 acrescentou um critério a avaliação dos LD - a base metodológica, ou seja, os LD deveriam propor situações de ensino e aprendizagem e distintos procedimentos cognitivos. Ele também se expandiu para todas as séries do Ensino Fundamental. O PNLD/1999 avaliou, pela primeira vez, os livros destinados aos anos finais do ensino fundamental $\left(5^{\circ}\right.$ ao $8^{\circ}$ ano $)$ nas áreas de Língua Portuguesa, Matemática, Ciências, História e Geografia.

Além disso, o PNLD/2001 voltou a analisar livros para os anos iniciais $\left(1^{\circ}\right.$ ao $4^{\circ}$ ano) nas áreas de Língua Portuguesa, Alfabetização, Matemática, Ciências e Estudos Sociais. Esse novo panorama do PNLD foi influenciado pela LDB 9.394/96 (BRASIL, 1996), a qual designava como dever do Estado ofertar o Ensino Fundamental, obrigatório e gratuito, aos educandos e, fornecer aos estudantes, material didático-escolar, transporte, alimentação e assistência à saúde por meio de programas suplementares do governo.

Somente no ano de 2003 foi instituído o Programa Nacional do Livro para o Ensino Médio (PNLEM), por meio da Resolução/CD/FNDE n 38, de 15 de outubro de 2003 (BRASIL, 2003). Essa resolução define que os livros selecionados nas escolas sejam decorrentes do processo de escolha feita pelos professores e que o financiamento desse programa ocorra com recursos provenientes da Lei Orçamentária da União e de contratos de empréstimos internacionais. A primeira avaliação do LD para o Ensino Médio, por sua vez, aconteceu em 2004 com análise dos livros de Português e Matemática.

Desde então, o processo de avaliação do PNLD acontece em ciclos trienais alternados, mediante um edital de convocação destinado a cada etapa da Educação Básica. No site do FNDE, encontram-se as diversas etapas de funcionamento do programa (Figura 1). 
FIGURA 1 - ETAPAS DO PROCESSO DE AVALIAÇÃO DOS LIVROS DIDÁTICOS NO BRASIL

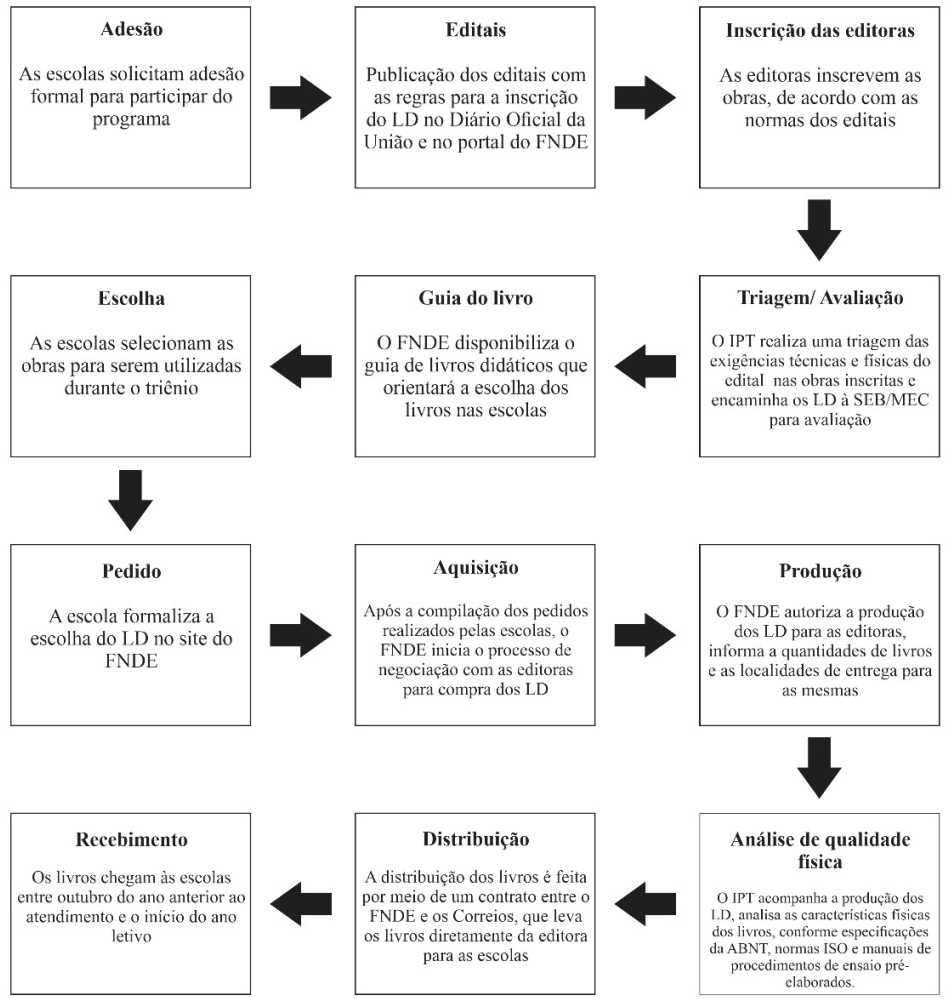

FONTE: Adaptado de Pinheiro (2018, p. 95).

A partir do ano de 2007, todas as regiões passaram a ser atendidas pelo programa e outras disciplinas foram gradualmente inseridas, inclusive a de Biologia.

A Resolução CD/FNDE n 60, de 20 de novembro de 2009 (BRASIL, 2009), estabeleceu novas regras para participação no PNLD. Dentre elas, temos que as redes públicas de ensino e as escolas federais deveriam aderir ao programa para receber os livros didáticos e incluir as escolas de ensino médio no âmbito de atendimento do PNLD, extinguindo, assim, o antigo PNLEM criado em 2003. O Decreto $n^{0}$ 7.084, em 2010 (BRASIL, 2010), regulamentou a avaliação, seleção, aquisição e distribuição de materiais didáticos para toda a Educação Básica e a regularidade da distribuição dos LD no Brasil. 
Di Giorgi et al. (2014, p. 1033) ressaltam que o PNLD de 2012 "apresenta avanços tecnológicos com a publicação de edital para formação de parcerias para estruturação e operação de serviço público e gratuito de disponibilização de materiais digitais a usuários da educação nacional". Para as editoras, foi imposto que as coleções apresentadas deveriam ter suas versões digitais. Isto se deu no contexto de mundialização das tecnologias digitais e de mais de duas décadas de implementação de políticas públicas de inserção de tecnologias digitais nas escolas públicas do Brasil na lógica do discurso de inclusão digital. Ademais, nesse ano o edital ampliou-se, contemplando todas as disciplinas do Ensino Médio, representando um fortalecimento dessa etapa da Educação Básica (BRASIL, 2011).

Assim, no PNLD 2015, edital lançado em 2013, pode-se inscrever obras didáticas codificadas como: obras do tipo 1 (obras multimídia compostas de livros impressos e digitais) ou obras do tipo 2 (obras impressas compostas por livros impressos e em portable document format - PDF) (BRASIL, 2013b).

O edital explicitava que as coleções didáticas inscritas necessitavam construir uma proposta pedagógica de ensino e aprendizagem que servissem ao longo dos três anos do nível médio, organizadas por ano e em conjuntos organizados em volumes. Essas coleções deveriam ser inéditas e apresentar os conteúdos de forma interdisciplinar, sempre que possível, fazendo referência a outras áreas do conhecimento.

O Manual do Professor deveria ter explicita a orientação teóricometodológica e deveria articular os conteúdos do livro entre si e com outras áreas do conhecimento, bibliografias adicionais e sugestões de leitura que contribuíssem para a mediação do conteúdo em sala de aula (BRASIL, 2013b).

Entretanto, a edição do PNLD 2018 não contemplou as obras didáticas com objetos educacionais digitais (OED), visto que não foi concretizada a compra dos OED pelo governo federal do edital anterior. Para Nitahara (2015), provavelmente devido à restrição orçamentária que assolava os cofres públicos. Além disso, as escolas públicas necessitam de melhorar sua infraestrutura para que seja possível o uso das tecnologias da informação e comunicação (TIC) como recurso didático.

Outro aspecto importante desse edital foi o de buscar garantir materiais didáticos que se adequassem às necessidades da Educação Brasileira propostas nas Diretrizes Curriculares Nacionais Gerais da Educação Básica - DCN (BRASIL, 2013a). Com isso, as obras aprovadas objetivavam estimular um trabalho pedagógico voltado para formação cidadã, na qual os estudantes pudessem estabelecer julgamentos, tomar decisões e ter criticidade quanto a sociedade, a ciência, a tecnologia, a cultura e a economia. Ademais, essas obras deveriam representar a sociedade por meio do respeito a imagem da mulher, 
dos afrodescendentes, dos indígenas e dos povos do campo; abordando questões de gênero com o intuito de promover o respeito e valorização da diversidade e promover a educação e cultura em direitos humanos (BRASIL, 2017).

Quanto à equipe de avaliadores das obras, vale ressaltar que cada dupla foi formada por um profissional indicado pela Universidade responsável pela avaliação de cada área e outro selecionado do Banco de Avaliadores do Ministério da Educação (BRASIL, 2017).

\section{PNLD de Biologia: suas relações e intencionalidades}

A disciplina escolar de Biologia participou, até o presente momento, de cinco edições deste Programa: PNLEM/2007, PNLEM/2009, PNLD/2012, $\mathrm{PNLD} / 2015$ e o mais recente, $\mathrm{PNLD} / 2018$.

$\mathrm{Na}$ análise dos Guias do Livro Didático (GLD) das edições do PNLD de Biologia, observamos que a avaliação pedagógica dessas obras foi realizada por diversos professores e pesquisadores das áreas da Biologia e do ensino de Biologia que atuam nas universidades e em escolas da Educação Básica das variadas regiões brasileiras.

O processo de avaliação foi sendo construído e ajustado a cada edital em consonância com as intencionalidades de cada governo. Todavia, de uma forma geral, ele se pautou em uma avaliação por critérios eliminatórios comuns a todas as áreas, critérios eliminatórios da área de Ciências da Natureza e suas Tecnologias e critérios eliminatórios específicos para o componente curricular Biologia.

Esses critérios são a base para os avaliadores elaborarem a Ficha de Avaliação dos LD inscritos, específica para cada edição e responsáveis por sustentar o parecer final de aprovação ou exclusão de cada obra. De modo geral, essas fichas analisam aspectos conceituais, éticos e metodológicos das obras didáticas, culminando na construção das resenhas de cada obra aprovada.

As resenhas apresentadas nos GLD expõem uma síntese avaliativa, sumário/ descrição das seções, discussão mais detalhada das obras e recomendações/ sugestões aos professores na utilização do LD, ressaltando a particularidade da proposta teórico-metodológica de cada coleção.

Nos anos de 2007 e 2008, os editais ainda eram vinculados ao PNLEM, instituído em 2003, e possuíam uma orientação para o trabalho autônomo dos professores, atuando como fontes e experiências para complementar sua atuação, 0 que não possuía destaque nas edições anteriores. A edição do PNLEM/2009 pautouse na reedição do GLD do PNLEM/2007, visto que, posteriormente, em 2011, foi realizada novamente a escolha de livros para o PNLD/2012 (BRASIL, 2008). 
Assim, as obras do PNLEM/2007 e 2009 consideravam o perfil do aluno e dos professores, as características gerais da escola pública e as situações de interação professor-aluno. Nesse sentido, os conteúdos e procedimentos apresentados nas obras deveriam estar compatíveis e atualizados com os conhecimentos correspondentes nas ciências e saberes de referência, além de ressaltar as demandas sociais e coerentes com as práticas educativas autônomas dos professores. Para tanto, nesses editais houve obras organizadas em volume único e obras com três volumes, na perspectiva seriada (BRASIL, 2008).

Na edição do PNLD/2012, o componente Biologia dizia preconizar obras que evidenciavam a preocupação com a escola pública brasileira e os seus atores, ressaltando pontos importantes para a formação dos adolescentes e na compreensão de modos de ensinar e aprender Biologia no Ensino Médio. Com isso, ressaltavam a necessidade da participação ativa dos alunos no processo de ensino e aprendizagem, garantida pelo professor. Para tanto, as obras aprovadas deveriam se fundamentar em: estabelecer conexões entre Biologia e cultura; explorar a dimensão histórica do conhecimento biológico; propiciar a professores e estudantes o uso de textos midiáticos e aparatos digitais; promover a articulação entre as propostas pedagógicas e a organização dos livros e relacionar o conhecimento científico e conhecimento escolar, com foco no científico (BRASIL, 2011).

Para Rodrigues e Gramowski (2014, p. 11), ao longo dos editais de 2007 a 2012 houve muitas mudanças,

referentes ao número de avaliadores, à quantidades de coleções analisadas e aos critérios adotados no âmbito do PNLD/PNLEM. Com relação aos critérios, privilegiou-se aspectos que podem ser adotados para as demais disciplinas escolares, não ressaltando, na maioria das vezes, os aspectos que distinguem as Ciências/Biologia como um campo de conhecimento próprio.

Para PNLD/2015, na avaliação pedagógica das obras de Biologia, a equipe de avaliadores contou com 37 professores e pesquisadores da área e ensino de Biologia, sendo que três lecionavam em escolas públicas estaduais e os demais eram professores e pesquisadores de universidades públicas (com mestrado ou doutorado em Educação e Biologia) (BRASIL, 2014). A inclusão de professores da Educação Básica, iniciativa da coordenação da avaliação, pode ter possibilitado maior criticidade ao processo avaliativo, tendo em vista que privilegiou a diversidade de olhares de profissionais que atuavam no ensino 
de Biologia. Tal edição do PNLD apresentou avanço nas discussões quanto às relações de gênero, étnico-raciais e da sexualidade humana (PINHEIRO, 2018).

Por fim, no PNLD/2018 os livros de Biologia deveriam buscar fortalecer a articulação entre as Ciências Biológicas e a vida, por meio das dimensões social, cultural, política, econômica, dentre outras. Assim, as obras aprovadas, apesar de ainda terem muitas lacunas, na visão dos avaliadores avançam na discussão da compreensão do conhecimento científico biológico como uma atividade humana e social e historicamente construída, logo com interferências e mudanças ao longo do tempo (BRASIL, 2017).

Ademais, os mesmos afirmaram buscar fazer discussões por meio de diversas abordagens metodológicas fundamentadas na contextualização e interdisciplinaridade quanto a: tradições científicas adotadas nos livros; tensionar a relação entre os conhecimentos biológicos e escolares bem como a linguagem em cada âmbito; relacionar a biodiversidade e sustentabilidade nas coleções; evidenciar a Biologia nas relações sociais e culturais; discutir sobre a sexualidade, as identidades de gênero e as questões étnico-raciais (BRASIL, 2017).

Assim, é possível observar que as mudanças nos critérios de avaliação pedagógica dos LD se dão em função, especialmente, da alteração na comissão avaliadora do MEC (RODRIGUES; GRAMOWSKI, 2014).

No quadro 1 abaixo apresentamos os dados entre as editoras e autores de cada uma das coleções aprovadas, em cada uma das edições, dos PNLD de Biologia (Quadro 1). 
QUADRO 1 - DADOS SOBRE AS EDITORAS E AUTORES ENVOLVIDOS NOS PNLD DE BIOLOGIA.

\begin{tabular}{|c|c|c|c|}
\hline Ano do PNLD & Editora & Título da obra & Autores \\
\hline \multirow{9}{*}{$\begin{array}{c}\text { PNLEM } \\
\text { 2007/2009 } \\
\text { OI: } 18 \\
\text { OA: } 9\end{array}$} & Ática & Biologia & $\begin{array}{c}\text { Sérgio Linhares } \\
\text { Fernando Gewandsznadjer }\end{array}$ \\
\hline & Ática & Biologia & Wilson Paulino \\
\hline & IBEP & Biologia & $\begin{array}{l}\text { Augusto Adolfo } \\
\text { Marcos Crozetta } \\
\text { Samuel Lago }\end{array}$ \\
\hline & Moderna & Biologia & $\begin{array}{c}\text { Gilberto Martho } \\
\text { José Amabis }\end{array}$ \\
\hline & Moderna & Biologia & $\begin{array}{l}\text { José Favaretto } \\
\text { Clarinda Pifaia }\end{array}$ \\
\hline & Nova Geração & Biologia & Janet Laurence \\
\hline & Saraiva & Biologia & $\begin{array}{l}\text { Sônia Lopes } \\
\text { Sérgio Rosso }\end{array}$ \\
\hline & Saraiva & Biologia & $\begin{array}{l}\text { César da Silva Júnior } \\
\text { Sezar Sasson } \\
\text { Nelson Caldini Júnior }\end{array}$ \\
\hline & Scipione & Biologia & Oswaldo Frota-Pessoa \\
\hline \multirow{8}{*}{$\begin{array}{l}\text { PNLD } 2012 \\
\text { OI: } 16 \\
\text { OA: } 9\end{array}$} & Ática & Biologia Hoje & $\begin{array}{c}\text { Sérgio Linhares } \\
\text { Fernando Gewandsznadjer }\end{array}$ \\
\hline & Ática & Novas Bases da Biologia & Nélio Bizzo \\
\hline & Edições SM & Ser Protagonista Biologia & $\begin{array}{c}\text { João Aguilar } \\
\text { (editor responsável) }\end{array}$ \\
\hline & FTD & Biologia & $\begin{array}{l}\text { Antônio Pezzi } \\
\text { Demétrio Gowdak } \\
\text { Neide Mattos }\end{array}$ \\
\hline & Moderna & Biologia & $\begin{array}{l}\text { Gilberto Martho } \\
\text { José Amabis }\end{array}$ \\
\hline & Nova Geração & $\begin{array}{l}\text { Biologia para a nova } \\
\text { geração }\end{array}$ & $\begin{array}{l}\text { Vivian Mendonça } \\
\text { Janet Laurence }\end{array}$ \\
\hline & Saraiva & $\mathrm{BIO}$ & $\begin{array}{c}\text { Sônia Lopes } \\
\text { Sérgio Rosso }\end{array}$ \\
\hline & Saraiva & Biologia & $\begin{array}{l}\text { César da Silva Júnior } \\
\text { Sezar Sasson } \\
\text { Nelson Caldini Júnior }\end{array}$ \\
\hline
\end{tabular}

(continua) 
(conclusão)

\begin{tabular}{|c|c|c|c|}
\hline Ano do PNLD & Editora & Título da obra & Autores \\
\hline \multirow{9}{*}{$\begin{array}{l}\text { PNLD } 2015 \\
\text { OI: } 16 \\
\text { OA: } 9\end{array}$} & AJS & Biologia & Vivian Mendonça \\
\hline & Ática & Biologia Hoje & $\begin{array}{c}\text { Sérgio Linhares } \\
\text { Fernando Gewandsznadjer }\end{array}$ \\
\hline & Ática & Novas Bases da Biologia & Nélio Bizzo \\
\hline & Edições SM & Ser Protagonista Biologia & $\begin{array}{l}\text { Tereza Osorio (editora } \\
\text { responsável) }\end{array}$ \\
\hline & Moderna & Biologia em contexto & $\begin{array}{c}\text { José Amabis } \\
\text { Gilberto Martho }\end{array}$ \\
\hline & Moderna & Conexões com a Biologia & $\begin{array}{c}\text { Rita Bröckelmann (editora } \\
\text { responsável) }\end{array}$ \\
\hline & Saraiva & $\mathrm{BIO}$ & $\begin{array}{l}\text { Sônia Lopes } \\
\text { Sérgio Rosso }\end{array}$ \\
\hline & Saraiva & Biologia & $\begin{array}{l}\text { César da Silva Júnior } \\
\text { Sezar Sasson } \\
\text { Nelson Caldini Júnior }\end{array}$ \\
\hline & Saraiva & $\begin{array}{l}\text { Biologia Unidade e } \\
\text { Diversidade }\end{array}$ & José Favaretto \\
\hline \multirow{10}{*}{$\begin{array}{l}\text { PNLD } 2018 \\
\text { OI: } 12 \\
\text { OA: } 10\end{array}$} & AJS & Biologia & Vivian Mendonça \\
\hline & Ática & Biologia Hoje & $\begin{array}{c}\text { Fernando Gewandsznajder } \\
\text { Helena Pacca } \\
\text { Sérgio Linhares }\end{array}$ \\
\hline & Edições SM & Ser Protagonista Biologia & $\begin{array}{l}\text { Lia Bezerra (editora } \\
\text { responsável) }\end{array}$ \\
\hline & FTD & $\begin{array}{l}\text { Biologia - Unidade e } \\
\text { Diversidade }\end{array}$ & José Favaretto \\
\hline & IBEP & $\begin{array}{c}\text { Integralis - Biologia: } \\
\text { Novas Bases }\end{array}$ & Nélio Bizzo \\
\hline & Moderna & $\begin{array}{l}\text { Biologia Moderna - } \\
\text { Amabis \& Martho }\end{array}$ & $\begin{array}{l}\text { Gilberto Martho } \\
\text { José Amabis }\end{array}$ \\
\hline & Moderna & Conexões com a Biologia & $\begin{array}{c}\text { Eloci Rios } \\
\text { Miguel Thompson }\end{array}$ \\
\hline & Quinteto & \#Contato Biologia & $\begin{array}{l}\text { Leandro a Godoy } \\
\text { Marcela Ogo }\end{array}$ \\
\hline & Saraiva & $\mathrm{BIO}$ & $\begin{array}{l}\text { Sônia Lopes } \\
\text { Sérgio Rosso }\end{array}$ \\
\hline & Saraiva & Biologia & $\begin{array}{l}\text { César da Silva Júnior } \\
\text { Sezar Sasson } \\
\text { Nelson Caldini Júnior }\end{array}$ \\
\hline
\end{tabular}

Legenda - OI: obras inscritas; AO: obras aprovadas.

FONTE: elaborada pelos autores. 
Constata-se que as editoras Ática, Moderna e Saraiva possuem algumas similaridades:

1) são as maiores e principais editoras do mercado brasileiro;

2) possuem as mesmas obras contempladas no PNLD de Biologia desde 2007;

3) cada uma delas normalmente aprova duas coleções em cada edição do PNLD;

4) possuem um grupo de autores recorrentes para os LD aprovados: Sônia Lopes e Sérgio Rosso; César da Silva Júnior, Sezar Sasson e Nelson Caldini Júnior (Saraiva); Gilberto Martho e José Amabis (Moderna); Sérgio Linhares e Fernando Gewandsznadjer (Ática).

A parceria intensa dos grupos editoriais (setor privado) e do Estado foi constatada, anteriormente, por meio de diversas pesquisas realizadas por Höfling (2006) e corroborada pelas informações do quadro supracitado, pois ambos dados evidenciam a forte centralização dos recursos públicos a um grupo menor que $20 \%$ do total de editoras inscritas no programa. Parecenos evidente que os LD são produzidos para um mercado com expectativas e demandas definidas, que são estabelecidas por meio do jogo de interesses entre os grupos editoriais e o Estado. Dessa maneira, os LD representam um mercado comercial de grande relevância sustentado pelos interesses das editoras e dos envolvidos no processo de avaliação que pautam o formato desse recurso didático (MARTINS; EICHELER, 2020).

Há um forte oligopólio dos LD no mercado brasileiro, vinculado a grandes grupos empresariais estrangeiros, que têm adquirido empresas familiares brasileiras que dominavam o setor dos livros didáticos nos últimos anos do século XX (CASSIANO, 2007). Esse oligopólio reflete o controle da indústria cultural, estrangulando a Educação Brasileira, fazendo dela um campo de negócios econômicos promissores.

Apesar dessa forte concentração, observa-se o crescimento de novas empresas no ramo das coleções didáticas (Edições SM - presente no PNLD 2012, 2015 e 2018 e Editora AJS - presente no PNLD 2015 e 2018). Esse fato pode ser um pequeno passo para descentralizar o poder dos grandes grupos editoriais vigentes ou para a constituição de novos oligopólios.

Os dados apresentados elucidam a constatação de oligopólio desenvolvido por essas empresas na comercialização do LD. As pesquisas de Castro e Lopes (2019) e Di Giorgi et al. (2014) salientam que para as editoras o segmento de livros didáticos é muito relevante ao mercado editorial brasileiro e movimenta cerca 1,3\% do orçamento do MEC, que em 2012, girava entorno de 63,7 bilhões anuais. Rosa (2017, p. 147) destaca ainda que o LD além de um produto de alta rentabilidade para os grupos editoriais, gera "uma indústria cultural sobre o LD, que aparentemente 'padroniza' grande parte do currículo e dos conteúdos das coleções didáticas". 
Na disputa por este mercado, as editoras utilizam-se de fortes estratégias de marketing para conquistar a clientela de um dos programas governamentais mais rentáveis do país. Di Giordi et al. (2014) problematizam o custo benefício do processo previamente consolidado do PNLD na contraposição ao sistema de apostilamento das escolas da rede municipal paulista. Eles nos asseguram ainda que com suas intercorrências, o PNLD deve ser apoiado, por ser um Programa que vem se adaptando e aperfeiçoando em consonância ao amadurecimento da Educação Brasileira e que atua "como uma estratégia para tentar frear a surpreendente tendência de apostilamento/invasão privada nas escolas públicas municipais paulistas" (DI GIORDI et al., 2014, p. 1053).

Nesse mesmo sentido, Bezzon e Diniz (2020) afirmam ser fundamental que os livros didáticos saiam dos extremos, ou seja, por uma lado se dizem ser neutros, imparciais e técnicos, sem relação com o compromisso políticopedagógico do trabalho docente e a formação dos estudantes; e por outro lado, os LD se prendem em subjetividades e debates políticos que distanciam do ensino do conhecimento científico sistematizado.

Apesar desses aspectos demonstrados nessa análise política e econômica do LD, esse recurso continua sendo um material de referência para o estudo do conhecimento científico, tanto para os docentes quanto para os estudantes da Educação Básica, sustentado por uma lógica de produção limitadora do conhecimento científico e que precariza as condições do trabalho docente.

\section{Considerações finais}

Por meio das discussões realizadas no decorrer deste artigo e o problema proposto de investigação, podemos explicitar que os contextos constituintes à política nacional do LD no Brasil, em especial, os editais e coleções aprovadas no PNLD de Biologia são: 1. Ao adotar um LD, o professor adquire um recurso didático que possui, intrínseco a ele, uma história e lógica de mundo, bem como de visão de Ciências, de escola e de ensino; 2. Há centralização dos recursos financeiros aos grandes grupos empresariais, que monopoliza o processo de avaliação e a sua atuação nas escolas; 3. Há intencionalidades comerciais e governamentais para a manutenção e porventura ampliação do PNLD na Educação Básica pública do país; e 4. O LD constitui-se enquanto uma mercadoria produzida e vendável por poucos grupos e a muitos estudantes. 
Refletindo sobre esses aspectos elencados, não compreendemos o LD como um constructo humano neutro e sem intencionalidade, visto que o governo e seus parceiros comerciais, exercem o controle do currículo escolar nas escolas públicas. Além disso, a centralização dos recursos financeiros aos grandes grupos empresariais, que monopoliza o processo de avaliação e a sua atuação nas escolas, pode influenciar os professores no processo de escolha do LD e nos seus modos de ensinar.

Ademais, conscientes que política, educação e economia são elementos inseparáveis da sociedade capitalista, o PNLD e o LD (produto final desse programa) não só podem influenciar as práticas pedagógicas, pelo fato de os conteúdos serem determinados social e politicamente, como favorecem a produção cultural pertinentes à sociedade capitalista, por meio do consumo do LD enquanto mercadoria.

Por meio da historicidade apresentada, observamos que a maneira como são conduzidas as políticas públicas do PNLD é contraditória, uma vez que por um lado contribui as necessidades formativas da Educação Brasileira e, por outro, influencia na movimentação de grandes cifras de poderosos grupos editoriais, os quais, em parceria com autores célebres, têm obras aprovadas em todas as edições dos PNLD de Biologia. Logo, são impactantes às práticas docentes, ao processo de ensino e aprendizagem e ao mercado editorial.

Assim, defendemos a manutenção do PNLD com equipes de avaliação sintonizadas aos propósitos de uma educação emancipadora, com mais professores da Educação Básica no processo avaliativo e que ocorra uma relação mais próxima dos critérios de avaliação das obras a um projeto de educação nacional pautado nos elementos essenciais ao desenvolvimento humano por meio da apropriação dos conteúdos científicos.

Apesar das coleções do PNLD 2018 avançarem na discussão da Biologia como uma ciência historicamente contextualizada, é, para tanto, fundamental que o LD ressalte o papel da História da Ciência na produção dos conhecimentos biológicos que sofre influências políticas, econômicas, sociais e culturais em cada época histórica, para que os estudantes tenham uma visão de mundo e Ciência mais abrangente e crítica. Corroborando com Martins e Eicheler (2020), os livros didáticos de Ciências e Biologia devem conter abordagens plurais, incentivar a desvinculação com o senso comum e possibilitar a reflexão sobre o excesso de reducionismos nas publicações nessa área. Com isso, é possível explicitar as condições humanas, históricas e contraditórias que permeiam um livro didático de qualidade (BEZZON; DINIZ, 2020). 
Portanto, mesmo agindo na atuação pedagógica com uma forte influência, muitas vezes, impondo-se no contexto, o LD não deve ser o responsável pela mediação didática do processo de ensino-aprendizagem, inibindo o trabalho criativo e pedagógico do docente, o qual deve ser o principal agente desta ação.

\section{REFERÊNCIAS}

ALBUQUERQUE, Eliana Borges Correia de; FERREIRA, Andrea Tereza Brito. Programa Nacional de Livro Didático (PNLD): mudanças nos livros de alfabetização e os usos que os professores fazem desse recurso em sala de aula. Ensaio, Rio de Janeiro, v. 27 , n. 103 , p. $250-270$, jun. 2019.

BEZZON, Rodolfo Zampieri; DINIZ, Renato Eugênio da Silva. O conceito de ecossistema em livros didáticos de biologia no ensino médio: abordagem e possíveis implicações. Educação em Revista, Belo Horizonte, v. 36, e195948, 2020.

BRASIL. Decreto-Lei n ${ }^{\circ} 1.006$, de 30 de dezembro de 1938. Estabelece as condições de produção, importação e utilização do livro didático. Diário Oficial da União, Poder Executivo, Rio de Janeiro, RJ, seção 1, p. 277, 5 jan. 1939.

BRASIL. Decreto-Lei n ${ }^{\circ} 8.460$, de 26 de dezembro de 1945. Consolida a legislação sobre as condições de produção, importação e utilização do livro. Diário Oficial da União, Poder Executivo, Rio de Janeiro, RJ, seção 1, p. 19208, 28 dez. 1945.

BRASIL. Decreto-Lei no 77.107, de 4 de fevereiro de 1976. Dispõe sobre a edição e distribuição de livros textos e dá outras providências. Diário Oficial da União, Poder Executivo, Brasília, DF, seção 1, p. 1681, 5 fev. 1976.

BRASIL. Ministério da Educação. Educação para Todos. Brasília, DF: MEC, [1985a]. Disponível em: http://www2.senado.leg.br/bdsf/bitstream/handle/id/200466/ educacaoparatodos.pdf? sequence=5. Acesso em: 12 jan. 2021 .

BRASIL. Decreto-Lei no 91.542 , de 19 de agosto de 1985. Institui o Programa Nacional do Livro Didático, dispõe sobre sua execução e dá outras providências. Diário Oficial da União, Poder Executivo, Brasília, DF, seção 1, p. 12178, 20 ago. 1985 b.

BRASIL. Ministério da Educação. Plano decenal de educação para todos. Brasília, DF: MEC, 1993. Disponível em: http://www.dominiopublico.gov.br/download/texto/ me001523.pdf. Acesso em: 12 jan. 2021.

BRASIL. Lei no 9.394, de 20 de dezembro de 1996. Estabelece as diretrizes e bases da Educação nacional. Diário Oficial da União, Brasília, seção 1, p. 27833, 23 dez. 1996. 
BRASIL. Resolução n 38, de 15 de outubro de 2003. Institui o PNLEM. Diário Oficial da União, Brasília, seção 1, p. 12, 23 out. 2003. Disponível em: https://www.jusbrasil. com.br/diarios/794739/pg-12-secao-1-diario-oficial-da-uniao-dou-de-23-10-2003. Acesso em: 5 set. 2021.

BRASIL. Biologia: catálogo do PNLEM/ 2009. Brasília: MEC/SEB, 2008.

BRASIL. Resolução no 60, de 20 de novembro de 2009. Dispõe sobre o Programa Nacional do Livro Didático (PNLD) para a educação básica. Diário Oficial da União, Brasília, seção 1, p. 36, 23 nov. 2009. Disponível em: https://www.jusbrasil.com.br/ diarios/1554738/pg-36-secao-1-diario-oficial-da-uniao-dou-de-23-11-2009. Acesso em: 5 set. 2021 .

BRASIL. Decreto-Lei n ${ }^{0} 7.084$, de 27 de janeiro de 2010. Dispõe sobre os programas de material didático e dá outras providências. Diário Oficial da União, Poder Executivo, Brasília, DF, seção 1, Edição Extra, p. 3, 27 jan. 2010.

BRASIL. Guia de livros didáticos: PNLD 2012 - Biologia: Ensino Médio. Brasília, DF: MEC/SEB, 2011.

BRASIL. Diretrizes Curriculares Nacionais Gerais da Educação Básica. Brasília, DF: $\mathrm{MEC} / \mathrm{SEB}, 2013 \mathrm{a}$.

BRASIL. Edital de convocação $n^{\circ} 1 / 2013$ : edital para o processo de inscrição e avaliação de obras didáticas para o Programa Nacional do Livro Didático PNLD 2015. Brasília, DF: MEC, $2013 b$.

BRASIL. Guia de livros didáticos: PNLD 2015 - Biologia: Ensino Médio. Brasília, DF: MEC/SEB, 2014.

BRASIL. Guia de livros didáticos: PNLD 2018 - Biologia: Ensino Médio. Brasília, DF: MEC/SEB, 2017.

CASSAB, Mariana et al. Análise de compêndios didáticos: tensões entre forças de estabilidade e mudança na história da disciplina escolar Biologia (1963-1970). Teias, Rio de Janeiro, v. 14, n. 28, p. 241-263, 2012.

CASSIANO, Célia Cristina de Figueiredo. O mercado do livro didático no Brasil: da criação do Programa Nacional do Livro Didático (PNLD) à entrada do capital internacional espanhol (1985-2007). 2007. 252f. Tese (Doutorado em Educação) Pontifícia Universidade Católica de São Paulo, São Paulo, 2007.

CASTRO, Sirlene Rodrigues Ferreira; LOPES, Carlos. O plágio nos livros didáticos e na visão de autores. Cadernos de Pesquisa, São Paulo, v. 49, n. 171, p. 224-242, 2019.

DI GIORGI, Cristiano Amaral Garboggini et al. Uma proposta de aperfeiçoamento do PNLD como política pública: o livro didático como capital cultural do aluno/família. Ensaio, Rio de Janeiro, v. 22, n. 85, p. 1027-1056, 2014. 
FERREIRA, Márcia Serra; SELLES, Sandra Escovedo. Entrelaçamentos históricos das Ciências Biológicas com a disciplina escolar Biologia: investigando a versão azul do BSCS. In: ENCONTRO NACIONAL DE PESQUISA EM EDUCAÇÃO EM CIÊNCIAS, 5., 2005, Bauru. Atas [...]. São Paulo: ABRAPEC, 2005.

FREITAG, Barbara; MOTTA, Valéria Rodrigues; COSTA, Wanderley Ferreira. O estado da arte do livro didático no Brasil. Brasília: INEP, 1987.

HÖFLING, Eloisa de Mattos. Notas para discussão quanto à implementação de programas de governo: em foco o Programa Nacional do Livro Didático. Educação \& Sociedade, Campinas, v. 21, n. 70, p. 159-170, 2000.

HÖFLING, Eloisa de Mattos. A trajetória do Programa Nacional do Livro Didático do Ministério da Educação no Brasil. In: FRACALANZA, Hilário; MEGID NETO, Jorge. O livro didático de Ciências no Brasil. Campinas, SP: Komedi, 2006. p. 21-31.

KOPNIN, Pavel Vassilyevitch. A dialética como lógica e teoria do conhecimento. Rio de Janeiro: Civilização Brasileira, 1978.

LAJOLO, Marisa. Livro didático: um (quase) manual de usuário. Em Aberto, Brasília, v. 19, n. 69 , p. 3-9, 1996.

LEFEBVRE, Henri. Lógica formal Lógica dialética. Rio de Janeiro: Civilização Brasileira, 1991.

MAGALHÃES, Justino. O manual escolar no quadro da história cultural: para uma historiografia do manual escolar em Portugal. Sísifo, Portugal, n. 1, p. 5-14, 2006.

MARANDINO, Marta; SELLES, Sandra Escovedo; FERREIRA, Márcia Serra. Ensino de Biologia: histórias e práticas em diferentes espaços educativos. São Paulo: Cortez, 2009.

MARTINS, Lígia Márcia. As aparências enganam: divergências entre o materialismo histórico dialético e as abordagens qualitativas em pesquisa. In: REUNIÃO ANUAL DA ANPED, 29., 2006, Caxambu. Anais [...]. Caxambu: ANPED, 2006. Tema: Educação, Cultura e Conhecimento: desafios e compromissos.

MARTINS, Isabel. Analisando livros didáticos na perspectiva dos estudos do discurso: compartilhando reflexões e sugerindo uma agenda para a pesquisa. In: MARTINS, Isabel; GOUVÊA, Guaracira; VILANOVA, Rita (org.). O livro didático de Ciências: contextos de exigência, critérios de seleção, práticas de leitura e uso em sala de aula. Rio de Janeiro: FAPERJ, 2012. p. 11-30.

MARTINS, Tais Oliveira; EICHLER, Marcelo Leandro. Neurociências cognitivas no estudo do sistema nervoso: um olhar crítico por meio do livro didático de educação básica. Investigações em Ensino de Ciências, Porto Alegre, v. 25, n. 2, p. 272-292, 2020.

NITAHARA, Akemi. Livro didático digital ainda não chegou aos estudantes. Agência Brasil, Rio de Janeiro, 2015. Disponível em: https://agenciabrasil.ebc.com.br/educacao/ noticia/2015-10/livro-didatico-digital-ainda-nao-chegou-aos-estudantes. Acesso em: 5 set. 2021. 
PINHEIRO, Regiane Machado de Sousa. O conceito de célula em livros didáticos de Biologia: análise sob uma perspectiva histórico-crítica. 2018. 165f. Dissertação (Mestrado em Educação em Ciências e Matemática) - Universidade Federal de Goiás, Goiânia, 2018.

ROSA, Marcelo D'Aquino. O Programa Nacional do Livro Didático (PNLD) e os livros didáticos de ciências. REPPE, Cornélio Procópio, v. 1, n. 2, p. 132-149, 2017.

RODRIGUES, Larissa Zancan; GRAMOWSKI, Vilmarise Bobato. Livros didáticos de Ciências e Biologia: os critérios de avaliação do PNLEM/PNLD em foco. In: SIMPÓSIO DE ENSINO DE CIÊNCIA E TECNOLOGIA - SINECT, 4., 2014. Ponta Grossa. Anais [...]. Ponta Grossa: UTFPR, 2014. p. 1-13.

SELLES, Sandra Escovedo; FERREIRA, Márcia Serra. Influências histórico-culturais nas representações sobre as estações do ano em livros didáticos de Ciências. Ciência \& Educação, Bauru, v. 10, n. 1, p. 101-110, 2004.

Texto recebido em 30/05/5021.

Texto aprovado em 05/08/2021. 